\title{
Economic considerations for bariatric surgery and morbid obesity
}

This article was published in the following Dove Press journal:

ClinicoEconomics and Outcomes Research

9 December 2009

Number of times this article has been viewed

\author{
Eldo E Frezza \\ Mitchell Wacthell' \\ Bradley Ewing ${ }^{2}$ \\ 'Center for Metabolic Disease and \\ Texas Tech University, Department \\ of Pathology, ${ }^{2}$ Rawls Business School, \\ Texas Tech University, Lubbock, \\ TX, USA
}

\begin{abstract}
The obesity epidemic is also an economic tragedy. This analysis evaluates the economic effects and the potential to improve the well-being of both individual and societal wealth. Econometric techniques should carefully assess the degree to which obesity affects declines in business output, employment, income, and tax revenues at the regional and national levels. Microeconomics assesses lost productivity and associated wages and profit. Macroeconomics assesses trends associated with employment, inflation, interest rates, money supply, and output. To decrease the adverse economic consequences of the obesity epidemic, policy makers must emphasize bariatric surgery as a cost-effective option for qualified patients. Early intervention, education, and tax rebates for obese individuals who undergo bariatric surgery and for medical centers and doctors would likely have positive economic effects on the whole economy in a few years.
\end{abstract}

Keywords: bariatric surgery, morbid obesity, economics

\section{Introduction}

Obesity afflicts 1 in 3 Americans, ${ }^{1}$ killing an estimated 100,000 each year. ${ }^{2}$ Because individual health deficits in aggregate adversely impact productivity and median family income, ${ }^{3}$ the obesity epidemic is also an economic tragedy, with adverse microeconomic and macroeconomic effects. Evaluating bariatric surgery in this context mandates consideration of surgical efficacy, costs, and benefits. This analysis evaluates the economical effect of needed policies on obesity with an eye to its clinical implications; the results will show bariatric surgery's potential to improve the well-being of both individual health and societal wealth.

\section{Relevant economic notions}

Microeconomics studies decision-making of individuals, households, and businesses under an assumed constraint of scarce resources. Microeconomic analyses can be used to predict outcomes associated with the purchase and consumption of goods and services and to assess how price and availability of goods and services affects purchase decisions. Microeconomic business analyses relate to production processes, location, hiring and compensation practices, pricing strategies, and the choice of products, and services to offer. Also assessed are individual productivity, and associated wage and profit determinants. In the context of such analyses, inefficiencies that yield negative consequences are said to be externalities. Externalities may be reduced when incentives of society and individuals are aligned; such a system of incentives would yield
Center for Metabolic Disease, 4208 2nd

Street, Lubbock TX 794I6, USA

Email eefrezza@msn.com 
wiser decisions with more optimal and efficient economic outcomes. An example would be a company that places the most nutritious items its cafeteria serves at the most accessible locations to encourage better eating habits, generating a healthier, more productive workforce less prone to absenteeism. Government support of fitness centers in Canada has been shown to be effective in reducing lost work days and in net economic benefits. ${ }^{4}$

Macroeconomics examines the movements and trends in economy-wide aggregate variables such as employment, inflation, interest rates, money supply and output. Perfectly competitive markets work imply that the value of the marginal product of the last worker hired is the market wage for the laborer, a relationship described by $\mathrm{VMP}=\mathrm{p} \times \mathrm{MP}=\mathrm{W}$, where VMP is the value of the marginal product, $p$ is the price, MP is the marginal product, and $\mathrm{W}$ is the wage of the laborer. Hence, VMP is the demand for labor. Obesity, by lowering MP, decreases the demand for labor. On a practical basis, this occurs when employers find expenses accrued by using an obese work force surpass the value of what the laborers produce; the response is to outsource work to thinner laborers (or laborers with less generous health benefits) or to reduce the use of labor entirely by automation. Because VMP $=\mathrm{W}$, real wages decline when VMP decreases. Decreased W can express itself as a decrease in the size of the paycheck and/or an increase in the cost of living. Current data suggest that inflation, rather than decreased paycheck amounts, will result from obesity.

The tradeoff between dollars used for health care and dollars used to increase general economic productivity can be evaluated within the context of a production possibilities frontier (PPF). Figure 1 displays two PPF curves on an imaginary island that produces only laptop computers, displayed on the $\mathrm{Y}$ axis and laparoscopic adjustable bands, displayed on the $\mathrm{X}$ axis. The numbers of laptop computers and laparoscopic adjustable bands produced at four different places on the island are measured, for the upper curve in 1980 and the bottom curve in 1995, after additional supplies of rubber were discovered, making laparoscopic band manufacture less expensive. The curves are said to be the ideal, points outside them being impossible and inside them being inefficient. The upper curve is within the bounds of the lower curve precisely because the relative lack of rubber made the production of laparoscopic bands inefficient. The bottom curve would also have been moved to the right had a more efficient means of manufacturing laparoscopic bands been created. A curve can also shift to the left, as might occur when a supplier ceases to exist. The notion can be applied to the economy in general. As obesity increases the cost of providing health care to a society's citizens, an inefficiency develops, such that a curve with adequate health care per person on the $\mathrm{X}$ axis and adequate housing per person on the $\mathrm{Y}$ axis is shifted to the left. Obesity, by diverting moneys from general technologic innovation, shifts the curve for the economy in general to the left. In the longer term, a lower capital stock results in a lower standard of living in the future.

Who really pays for the prevalence of obesity in the economy? Answering this question requires an understanding of the gross domestic product. The famed GDP (Y) comprises four components, consumption (C), investment (I), government $(\mathrm{G})$ and net exports (X). If each component is viewed as a proportion of $\mathrm{Y}$, an equation can be created, $1=\mathrm{Y}=\mathrm{C}+$ $\mathrm{G}+\mathrm{I}+\mathrm{X}$. Viewed proportionately, rises in $\mathrm{G}$ required to cover additional government provided health benefits requires I, X, or $\mathrm{C}$ to fall alone or in combination. Over half the direct medical cost of obesity is born by publicly funded programs, such as Medicare and Medicaid. ${ }^{1}$ Analogous to the situation with respect to the general economy, as the proportion of government spending that accrues from obesity increases, the fraction available for other government services, such as education and building roads, decreases. In general, the result is less likely a trade off within the arena of government spending than an increment in G. Given decreased VMP from increased insurance premiums, I is the most likely to decrease, decreasing purchases of new equipment, machinery, and factories. A dollar spent on I will generally yield more future output than a dollar spent on G. Moreover, decreased VMP means decreased W, which decreases consumer spending C. Given an increased cost of employment, any demand for a product is more likely to be satisfied by the labor in other thinner nations, decreasing net exports $\mathrm{X}$. The end result is an increase in $\mathrm{G}$ and a decrease in I, X, and C. Thus, $\mathrm{C}$ falls along with $\mathrm{I}$. The resultant increase in government debt has two negative effects. First, taxes must rise, decreasing the amount of money in the economy itself. Second, borrowing exerts an upward pressure on interest rates, given that government competes with the private sector for funding of loans. The analysis, generalized to the federal level, is analogous to that used at the state level. Ultimately, the conclusion that all pay obesity's costs is inescapable.

\section{Costs of obesity and benefits of bariatric surgery}

Real dollar figures make the above more meaningful. In 1998, medical spending for obesity accounted for $9.1 \%$ of US health expenditures, ${ }^{5}$ with an estimated annual 

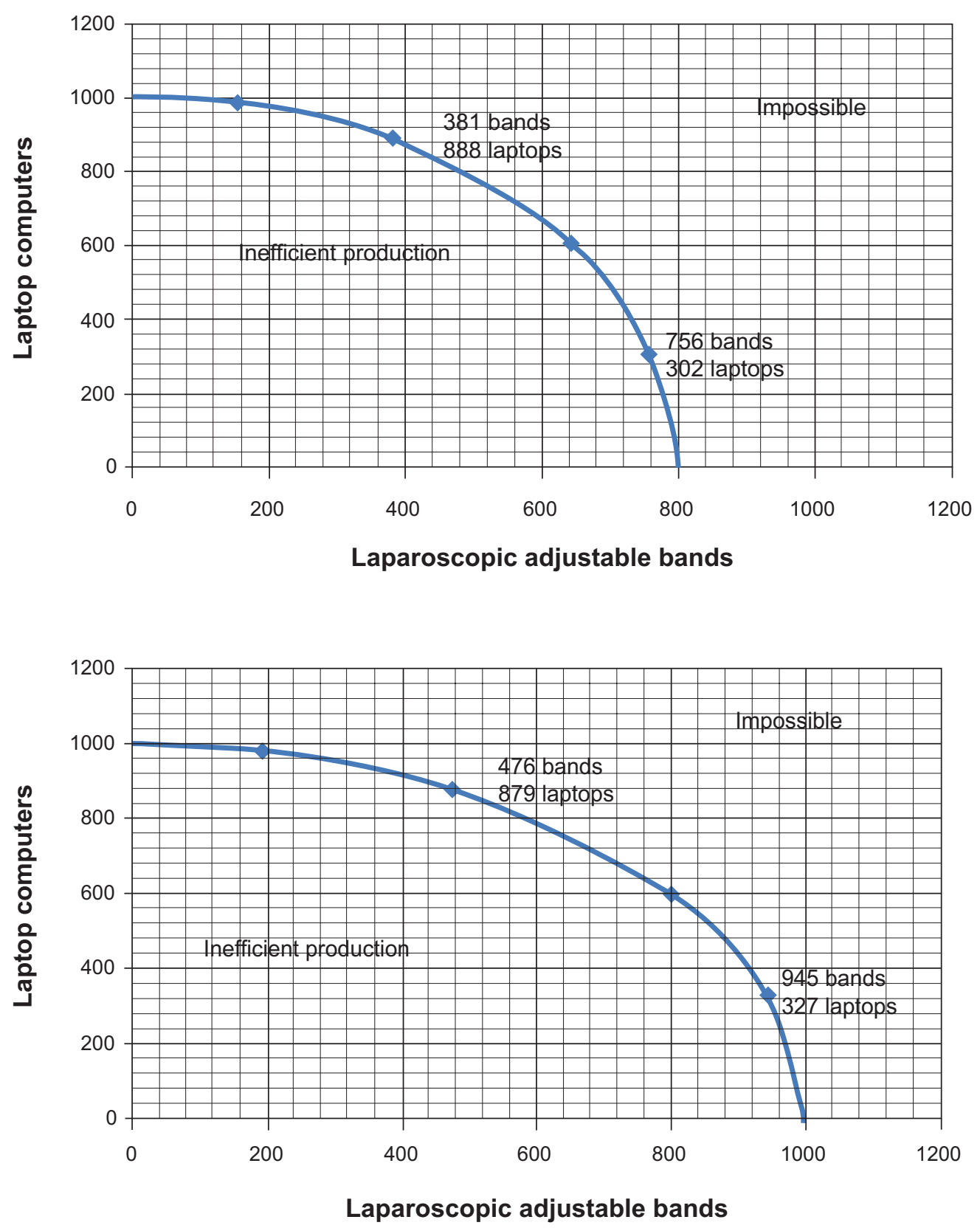

Figure I Production possibility frontier curves for an imaginary island that produced laptop computers and laparoscopic adjustable bands before (top half) and after (bottom half) the discovery of new rubber sources that made the bands less expensive to produce.

$\$ 74$ billion in direct costs in 2008 US dollars. ${ }^{6}$ By 2008, the estimated direct medical cost had risen to $\$ 143$ billion. ${ }^{4}$ Obesity increases the negative effects of diabetes, dislipidemia, and hypertension on medical spending by $33 \%$, $60 \%$, and $58 \%$ and the number of lost workdays by $180 \%$, $72 \%$, and $221 \%$, respectively. ${ }^{7}$ An evaluation of workman's compensation data revealed that the number of lost workdays was almost 13 times higher, medical claims costs were 7 times higher, and indemnity claims costs were 11 times higher among the heaviest employees compared with those of recommended weight. ${ }^{8}$ What this means is that obesity costs a firm with 1,000 employees about $\$ 285,000$ per year. ${ }^{4}$ The results extend to the economy as a whole: New Mexico was estimated to have experienced a negative economic impact accounting for $2.5 \%$ of its gross state product, with an associated 7,300 lost jobs. ${ }^{9}$

Bariatric surgery has been shown to be an effective treatment for morbid obesity and its co-morbidities. Two years after the procedure, bariatric surgery patients are 0.38 times as likely to be hypertensive, 0.02 times as likely to 
have diabetes, and 0.10 as likely to have hypertriglyceridemia as are non-surgically treated controls. ${ }^{10}$ In terms of years of added life, gastric bypass yields an estimated 2.6 added years for a 40 year old obese woman. ${ }^{11}$ The effect on diabetes is often independent of its effect on weight control; when matched with patients of equivalent weights, one study found that those who undergo gastric bypass show lower levels of serum leptin, fasting insulin, and blood glucose. ${ }^{12}$ Indeed, for patients who undergo gastric bypass and biliopancreatic diversion, the data show that $80 \%$ to $100 \%$ of severely diabetic patients achieve durable euglycemia, usually within days of the procedure. ${ }^{13}$ The least invasive procedure, laparoscopic adjustable gastric banding, yields control of both hypertension and diabetes in $85.4 \%$ of patients. ${ }^{14}$ The more restrictive procedures effect their changes in part hormonally; laparoscopic sleeve gastrectomy alters ghrelin levels, an effect not seen with gastric banding. ${ }^{15}$ Studies of non-obese diabetic rats suggest that the small intestine bears much of the responsibility for euglycemia. ${ }^{16}$ That restriction related changes in hormones may play a role in weight loss itself is shown a study that showed that patients who underwent sleeve gastrectomy had a better weight loss and a lower craving for sweets than did those who underwent gastric banding. ${ }^{17}$ Non-operative techniques simply lack efficacy when compared to bariatric surgery.

\section{Government commitments}

Government policy changes that might favor bariatric surgery should be considered after careful study. Analyses must be conducted to determine the risk factors associated with treatment success and failure, shedding light on the "market forces from the demand side to better determine who should receive the surgery. Continuous quality improvement is mandatory to convince payers of the value of the surgery, with a focus first on life-cycle costs of bariatric procedures, centers/facilities, technological advances, and quality assurance processes. This would be followed by analyses of continuous quality improvement programs, with attention directed to: delivery and quality, assessment, cost containment, financial improvement, cost reduction strategies, cost savings, service design processes, and forcasting. Attention would then focus on clinical and economic outcomes, with a generalized national scope. Clinical metrics would include 30-day mortality rates for those undergoing the surgery and proportion of patients within the five year period after surgery that require second procedures. Patients should be followed over their lifetimes, so as to create the most accurate cost-benefit and cost effectiveness analyses. ${ }^{11}$ Econometric techniques should carefully assess the degree to which obesity affects declines in business output, employment, income, and tax revenues at the regional and national levels. Because clinical outcomes are inherently linked to a variety of economic benefits and costs, such as work life expectancy, absenteeism, societal welfare, costbenefit models must explore a wide array of parameters, with reassessment provided with every major technologic advance. Notwithstanding these research objectives, the evidence is strong enough to merit consideration of tax incentives for bariatric surgical centers and reductions in malpractice burdens for those who perform the procedures, as well as increased moneys for the training of bariatric surgeons.

The major disease syndrome accorded to obesity, the metabolic syndrome, comprises high blood pressure, high cholesterol, high triglycerides, diabetes or glucose intolerance, respiratory difficulties, cardiovascular difficulties, and an increased risk of deep venous thrombosis, as well as multiple other problems. Weight loss ameliorates and often completely resolves most of diseases related to metabolic syndrome. Bariatric surgery has been shown to dramatically improve these medical conditions, to the extent that formerly obese persons can live more productive and complete lives; no other form of weight control has comparable efficacy. To decrease the adverse economic consequences of the obesity epidemic, policy makers must emphasize bariatric surgery as a costeffective option for qualified patients. A general policy program should first be directed to individual decisions with respect to lifestyle changes. Reductions in obesity, through incentives with respect to exercise programs and nutrition, such as a tax on sugar, would reduce negative externalities to some degree. Tax rebates for obese individuals who undergo bariatric surgery would likely be more efficient because the money is directed to those most likely to accrue increased health costs. Education is vital, both with respect to increasing knowledge of the costs of obesity and to explaining when bariatric surgery is an appropriate option. Medical centers and doctors could be incentivized through tax rebates to perform bariatric surgery. The costs of such a plan would likely be offset by the positive economic impacts of surgery within a few years. ${ }^{18}$

\section{Disclosures}

The authors declare no conflicts of interest.

\section{References}

1. Statistics USNCfH. Age-adjusted percent distributions of body mass index (BMI) among persons 18 years old and over by selected characteristics: 2003-2006. Vol. 2009: Centers for Disease Control, 2009.

2. NIDDK. Weight-control Information Network. Vol. 2009. Bethesda, MD: NIDDK; 2009. 
3. Phelps CE. Health Economics. 4th ed. Reading, MA: Addison-Wesley; 2009.

4. Stanton KR. Obesity causes, related costs and tax consequences: recommendations for Maryland support of health and fitness improving activities., Vol. 2009. Baltimore, MD: University of Baltimore; 2008.

5. Finkelstein EA, Fiebelkorn IC, Wang G. National medical spending attributable to overweight and obesity: how much, and who's paying? Health Aff (Millwood). 2003;Suppl Web Exclusives:W3219-26.

6. Wolf AM, Colditz GA. Current estimates of the economic cost of obesity in the United States. Obes Res. 1998;6(2):97-106.

7. Sullivan PW, Ghushchyan V, Ben-Joseph RH. The effect of obesity and cardiometabolic risk factors on expenditures and productivity in the United States. Obesity (Silver Spring). 2008;16(9):2155-2162.

8. Ostbye T, Dement JM, Krause KM. Obesity and workers' compensation: results from the Duke Health and Safety Surveillance System. Arch Intern Med. 2007;167(8):766-773.

9. Frezza EE, Wachtel MS, Ewing BT. The impact of morbid obesity on the state economy: an initial evaluation. Surg Obes Relat Dis. 2006;2(5):504-508.

10. Sjostrom CD, Lissner L, Wedel H, Sjostrom L. Reduction in incidence of diabetes, hypertension and lipid disturbances after intentional weight loss induced by bariatric surgery: the SOS Intervention Study. Obes Res. 1999;7(5):477-484.
11. Pope GD, Finlayson SR, Kemp JA, Birkmeyer JD. Life expectancy benefits of gastric bypass surgery. Surg Innov. 2006;13(4):265-273.

12. Hickey MS, Pories WJ, MacDonald KG Jr, et al. A new paradigm for type 2 diabetes mellitus: could it be a disease of the foregut? Ann Surg. 1998;227(5):637-643; discussion 643-644.

13. Rubino F, Gagner M. Potential of surgery for curing type 2 diabetes mellitus. Ann Surg. 2002;236(5):554-559.

14. Ganesh R, Leese T, Rao AD, Baladas HG. Laparoscopic adjustable gastric banding for severe obesity. Singapore Med J. 2006;47(8):661-669.

15. Langer FB, Reza Hoda MA, Bohdjalian A, et al. Sleeve gastrectomy and gastric banding: effects on plasma ghrelin levels. Obes Surg. 2005;15(7):1024-1029.

16. Rubino F, Forgione A, Cummings DE, et al. The mechanism of diabetes control after gastrointestinal bypass surgery reveals a role of the proximal small intestine in the pathophysiology of type 2 diabetes. Ann Surg. 2006;244(5):741-749.

17. Himpens J, Dapri G, Cadiere GB. A prospective randomized study between laparoscopic gastric banding and laparoscopic isolated sleeve gastrectomy: results after 1 and 3 years. Obes Surg. 2006;16(11):1450-1456.

18. Wolf AM, Manson JE, Colditz GA. The economic impact of overweight, obesity, and weight loss. In: Eckel RH, ed. Obesity; Mechanisms and Clinical Management. Philadelphia, PA: Lippincott Williams and Wilkens, 2003:523-549.
ClinicoEconomics and Outcomes Research

\section{Publish your work in this journal}

ClinicoEconomics \& Outcomes Research is an international, peerreviewed open-access journal focusing on Health Technology Assessment, Pharmacoeconomics and Outcomes Research in the areas of diagnosis, medical devices, and clinical, surgical and pharmacological intervention. The economic impact of health policy and health systems

\section{Dovepress}

organization also constitute important areas of coverage. The manuscript management system is completely online and includes a very quick and fair peer-review system, which is all easy to use. Visit http://www.dovepress.com/testimonials.php to read real quotes from published authors. 